China, and excellent silk may be made by dexterous management with a good hand-reel. Organzine is considerably twisted and is the choicest. Tram is made from inferior cocoons and is but slightly twisted. or wool. valueless for manufacturing purposes, several of them com-
bined going to make the staple of commerce. The persons employed in unwinding silk are mostly women, one stand charge. The basin is made of copper, and, in the large at the control of the operator. The cocoons are plunge into the water. when it is near the boiling point, and moved
about so that the gum which fastens the threads becomes about so that the gum which fastens the threads becomes
uniformly and thoroughly sof tened. They are then beaten the loose threads readily fasten to them. After beating a short time, the operator gets all the cocoons fastened, and,
taking the bundle of threads, shakes the cocoons till each hangs but by a single one. She now takes up five or more
threads (brins). according to the quality of silk wanted, threads (brins). according to the quality of silk wanted,
unites them, and introduces the combined staple or strand
( fil) into a little glass eye on one side of the basin. She then forms a second similar strand and introduces it into a
second eye on the other side. The strands are then brought together, twisted several times, separated above the twist,
and introduced into two other glass eyes or ringlets, through
which they are led, one to each end of the reel or tambour, which they are led, one to each end of the reel or tambour, which is kept revolving in a steady, rapid manner, and to
which is also given a certain back-and-forth side motion. The great object in reeling is to get the threads uniform,
rounded, well joined, properly freed from moisture, and rounded, well joined, properly freed from moisture, and
so crossed on the reel that they will not stick or glaze, as it
is termed. These objects are attained by the twisting and
the to-and-fro lateral movement of the reel, as also by the to-and-fro lateral movement of the reel, as also by
properly regulating the distance between reel and basin. The uniformity of the thread depends on the skill of the
operator, who must supply a new thread as soon as one
begins to give out. This is called nourishing the silk, and is done by dexterously casting, with the thumb, the new thread upon the combined strand, to which it immediately of a cocoon gradually gets lighter and finer as it approaches the end, and the uniformity of strand does not entirely
depend on the uniformity in number of the individual depend on the uniformity in number of the individual
threads forming it. Whenever the silk rises in locks the
temperature of the water is known to be too hot, and when it unwinds with difficulty the temperature is, on the con-
tr iry, oo low. The operator is supplied with a skimmer triry, loo low. The operator is supplied with a skimmer
with which to remove all chrysalides and refuse silk; also,
with a basin of cold water in which to cool her fingers, with a basin of cold water in which to cool her fingers,
which are being constantly dipped in the hot basin. This constitutes the whole operation of unwinding, but before
the skeins, as they come from the reel, are ready for the the skeins, as they come from the reel, are ready for the
rnanufacturer they must undergo still further manipulation. rnanufacturer they must undergo still further manipulation.
The staple is first passed through a cleanser, consisting of a
clasp lined with cloth, which catches any loose silk or other matter that may be adhering to it. It is then further
cleanse and purge by being passed through four similar cleansed and purged by being passed through four similar yard, then doubled and again twisted about 400 times to the
yard. It is finally run on to reels about $11 / 2$ feet in diameter, and taken off and twisted in a peculiar knot or hank. motion is kept up, so as to produce the diagonal crossing of
the strands, and it will be readily understood that each the strands, and it will be readily understood that each
staple is, in the end, composed of ten or more of the simple threads first spun by the worm.
"The loose or flock silk, together with all which, from one cause or another, cannot be reeled, is soaked in water for three days, boiled for one half hour in clear lye, washed
in rain-water, and when dry, carded, and spun it makes an inferior floss silk."
In order to better illustrate these principles, we have introduced figures of three reels. Fig. 5 is the old Piedmontes
reel, which for many years held its supremacy, and which
has been the foundation of numerous improved reels. It i formed of four bars or arms, and is usually about a yard in so that it may fold inwards towards the center when so that it may fold inwards towards the center when it
becomes necessary to slacken the silk in order to carefully
remove it from the reel. The lateral movement so necessary remove it from the reel. The lateral movement so necessary
in order that the consecutive circles shall not stick together is gained in rather a clumsy manner by means of cogs. The
strands after being twisted several times at $c$, in order to round and smooth the threads by friction, are passed ove
the guides, $b b$, which are inserted in the traversing bar, $a$ To this bar the lateral movement is imparted by a pin con-
nected with the outer circumference of the cog.wheel, $d$. This nected with the outer circumference of the cog-wheel, $d$. This
is connected at $e$ with the cog revolving with the shaft of the
recl. $f$ represents a charcoal-furnace under the copper basin, recl. $f$ represents a charcoal-furnace under the copper basin,
$g$. The criss-bar, $h$, to which arc attached the glass eyes through which the threads from the cocoons first pass, is usually widened into a shelf, upon which to place the broo
and the cold water for the reeler's fingers. Figs. 6 and 7 represent, respectively, a plane view, seen
from above, and a longitudinal vertical section of an old from above, and a longitudinal vertical section of an ol the principles of which are employt
reeling establishments of to-day. $a$. The oblong water-basin heated by a charcoal-furnace
or by steam, and frequently divided by partitions.
$b b$. Hooked wires or eyelets to guide several threads and keep them apart.
$c c$. Points where the threads are twisted upon each other to clean their surfaces and compactly round them.
$d$. Cylinder on shaft, with a spiral groove in its surface,
in which fits a pin from the traversing-bar, thus giving the in which fits a pin from the traversing-bar, thus giving the lateral movement to the thread which goes through a guider
on the front end of the bar, which moves through the arc
of a circle. $e$. The reel.

$f$. Pulleys which transmit by a belt the rotary motion of
the cylinder, $d$, the reel, $e$, that connected with the reel
being the smaller of the two. $g$. Friction lever, for tightening or slackening the endless cord, in setting or stopping the winding operation. There
is usually a series of such reels in one apartment, driven by shown, can be stopped at pleasure. In case the reels are consists the whole secret of the successful rearing of silkshown, can be stopped at pleasure. In case the reels are worms on this plant; and if care be had in this respect there
driven by a steam engine, stop-cocks and pipes are so ar- will be no appreciable difference in the silk crop from Osage
ranged that the water in every basin can be instantly or orange as compared with that from mulberry. ranged that the water in every basin can be instantly or orange as compared with that from mulberry.
gradually heated by steam If desired to run the reel by : Should the worms, from whatever cause, hatch before $d$, or of the reel, $e$.
Fig. 8 represents a hand reel, of much the same style as I will dried lettuce leaves. It will, however, be worse than a the last, set up and ready for work. This machine was
illustrated in the American Artisan for February, 1874 , in
the course of an article by W. V. Andrews, of Brooklyn. It the same principle as the old French reel of forty years ago.
$a$. Tin basin with copper bottom for holding the water in
which the cocoons are boiled, fitting tightly over the tray, $b$.
$b$. Square tin tray for reception of cocoons, etc. $c$. Short stick inserted in a holder, on which the ends
cocoons are wound, so as to be ready for use. $e$. Cock to let off water from the basin. This should be
one every night after use. $f$. Door of furnace lined with fire-bricks, wherein the $g$. Flue-pipe to carry off fumes; this, as supplied, is short,
he length and direction in which it may be carried varying every case. It is necessary that all the charcoal fumes
hould be carried either into a chimney or into the open $h h$. Glass eyes on wire holders, through which the threads
fom the cocons pass upward to the pulleys at $k$. It is of mreadance that the glass eyes should be so placed that the pulleys at $k$, and also from the pulleys to the top of the
wheel at $o$ (except so far as when diverted laterally by the why guider at $l l l)$; friction is thus reduced to a minimum,
and the elasticity of the thread preserved.
$i$. A former arrangement for twisting $i$. A former arrangement for twisting the threads one
upon the other; this is now discontinued as unnecessary,
since the twist given to the threads at $k$ and continued
downward to the point $h$ effects its purpose with a minimum since the twist given to the threads at $k$ and continued
downward to the point $h$ effects its purpose with a minimum
of friction, and produces a superior thread. This twist is of friction, and produces a superior thread. This twist is
effected by the very simple method of passing one thread
round the other, as shown in the small drawing of the pul. ound the other, as shown in the small drawing of the pul
$k, k$. Rollers or pulleys revolving on bent wire stands, $k k$. Rollers or pulleys
over which the threads pass.

hreads pass to reach on Glass eyes may be substituted for $n=$ A grooved arrangement by means of which the long
$n$.
uider working to-and-fro distributes the thread to the reel

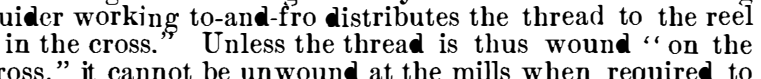
e thrown, and is, therefore, unsalable.
o. The top of the reel on which the

$o$. The top of the reel on which the silk is wound. One
the arms is furnished with the screw-hinge attached, by means of which the length of the arm is diminished to take
and $p$. Handle of the machine. (The letter in the cut is in The adult reeler sits on the stool in front of the cocoons,
and the other stool is occupied by the child who turns the FOOD PLANTS.

The traditional food plant of the silkworm is the mulberr (botanical genus Morus). There are two species of mul-
berry indigenous to the United States, namely, the red mul-
berry (Morus rubra) and the small-leaved mulberry (Morus
parvifolia), neither of which is suitable silk worm food. I ither refuse its loaves the worms upon rubra, but they
eirel or dwindle and soon die upon it. The imported species which are most used are the
white $(M$. albal, the Multicaulis, and the black (M: nigra). This last is inferior to the other two as silkworm food.
The mulberry grows readily, being easily propagated by cuttings or layers or from the seed. The white mulberry,
in particular, grows well from cuttings, and this is perhaps
the readiest and most economical method of planting to seThe cuttings should be started in rows, 3 or 4 inches
The stock. apart, in ground prepared by deep plowing and harrowing. before an eye in every case. They should be almost en-
tirely buried. The quickest way to get a supply of leaves is to grow $d$ warfs. Set out the young trees from the nur-
sery in rows 10 to 15 feet apart, and 6 to 8 feet between the sery in rows 10 to 15 feet apart, and 6 to 8 feet between the
rows, and form the crown of the tree by cutting down to a
foot or so from the ground. The height of the tree and its orm are easily regralitet by pruning, and upon this process he ease with which the leaves may be gathered when de
ired. The pruning may be done in February or March

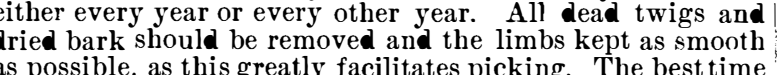
for planting is in the fall, from frost until December, and in Fe spring, from March until May.

For growing standard high trees, a practical raiser gives
he following directions: The cutting should remain two
years in the nursery without pruning. The third vear it is years in the nursery without pruning. The third year it is
cut down close to the ground and transplanted. Thlie finest shot is then allowed to grow, and in good. Tand it will
reach a height of 8 or 10 feet in one season. The fourth ear it is cut back to 6 feet or thereabouts. Then, the three
or four terminal buds only being allowed to grow, all others are removed as often as they appear, by passing the hand
a d along the stem.
The Moretti, a variety of the white mulberry, is profitably rown in the form of a hedge, and the large size of it
leaves makes it a very desirable variety. OSAGE ORANGE.

The cultivation of the Osage orange (Maclura aurantiaca) of giving detailed instructions on the subject. Very genewhich are particularly adapted to silk culture, its leaves apital. Indeed, as the hedges need trimming, the cutting
off of the new year's growth, as the leaves may be wanted Those who ure this plant as silkworm food must, however, bear in mind that the shoots from a hedgerow become very
vigorous and succulent by the time the worms are in the vigorous and succulent by the time the worms are in the Tast age. These more milky and succulent terminal leaves
hould be thrown aside and not used, as they are apt to in-

In avoiding these more tender leaves, and using only the
dider and firmer ones, especially when the worms are large, waste of time to attempt to feed them entirely on these
leaves, or, in fact, on any other plants than the two here BENNETT'S GELATINE EMULSION PROCESS. By W. WAINWRight, JR.*

IN January, 1878, a writer in the "Photographic Almaac" said of gelatine, "thlat it is equal in value to collodion, yet evident." The same writer goes tin to say with collond, with due knowledge of the treatment necessary at the
fter stages, may arrive at a pitch of sensitiveness which is after stages, may arrive at a pitch of sensitiveness which is
scarcely attainable with gelatine without detriment to other Since the articie

Since the articie referred to was written, a revolution has
aken place with regard to gelatine. Instead of being equal in value to collodion, it is far superior to it in point of senquickness in developing. This change is owing to the free
The method of working gelatine-a result at which he proper after much careful experiment. I do not claim for the negatives and prints I send around to-night that they are
the best or the quickest that gelatine can produce. I show the best or the quickest that gelatine can produce. I show
them as an amateur, and as examples of what any one may o by following strictly Mr. Bennett's formula.
There are many formula of various process published, There are many formula of various process published,
but it is a question how many of them are workable by orAs soon as Mr. Bente

As soon as Mr. Bennett had published his formula (and
ven before, as the process had been shown to many), the market was supplied with gelatine plates by various makers
who had never before produced any thing like them in rapidity or quality, nor can they now, except they follow his Only the other day it was a matter of speculation whether
elaine plates could be used in the studio. Now many are using them to the entire exclusion of wet plates.
The process claims for itself, I think, the following special
peculiarities, the combination of all of which leads to suc1st. Lengthened emulsification

2d. Thorough washing, so that all the salts are elimi3d. The power of using a strong alkaline developer without any restraining bromide.
4 th. The working in au extra non-actinic light.
The negatives I exhibit are all taken with a r

Thear lens in sunlight. The exposure in April on trees is 15 seconds, and on all the others 7 to 10 seconds, with the
exception of one. which is nearly instantaneous. I have exception of one. which is nearly instantaneous. I have
not, myself, gone in for very extra rilyidity, which would
entail emulsifying for from three to five dias, but have contented myself for ordinary landscape work with an
emulsification of $21 / 2$ davs, and thorough washing, say 12 (a)

There is little doubt in my mind that owing to the liberality of Mr. Bennett a great impetus has been given to
gelatine plates, and the trade and public will much benefit gelatine plates, and the trade and public will much benefit
thereby. The formula $\mathbf{P}$ use is what Mr. Bennett has al 7 grains bromide ammonia 11 do. silver.
90 do. gelatine.

I send round the prints and negatives together, so that members may be able to compare them together, and they
will then see how vigorous and soft a print can be obtained rom a comparatively weak negative.

\section{PHOTOGRAPHY IN COLORS.}

By M. K. Versnaeyen.

MANY people, latterly, have erroneously given to different ystems of painting on photography the misplaced title
"photography in colors." This was too much to say of the "ngenious results, some of which were obtained by the transparence of the photographic image, some by other means.
Nay, attempts were even made to make us believe that photographic proofs, tinted by oil or water-colors, were proofs
obtained directly in colors. The only process which, up to the present time, has really deserved the name of "photo-
graphy in colors" is that of M. Ducos du Hauron, but it is graphy in colors" is that of M. Ducos du Hauron, but it is colors obtained not always being of the required tone. To oubt not that M. Ducos du Hauron will, sooner or later M. Germeuil Bonnaud's process of photographing in colors
we use this term intentionally because it is the only term we use this term intentionally, because it is the only term
trictly applicable-simply consists in cansing the photostrictly applicable- simply consists in cassing the photo-
graphic action to operate directly on the color. To this end
M. Germeuil Bonnaud has carefully sought the means of 1 Germeuil Bonnaud has carefully sought the means of soluble, so that it might be able to resist the numerous
baths necessary to the photographic process. When this process is used, all the operations remain the same as in the
ordinary method, with this great advantage, that the im pressions made by the silver salts on the colored background give precisely the effect of the original model, and have not
that hardness of tone that generally characterizes a " re ouched" photograph. The print comes out of the bath completely colored. Thanks to the chemical agents and
the sensitive paper used by M. Germenil Bonnaud, the col-
lors and the photograph are henceforward indelibly united. lors and the photograph are henceforward indelibly united.
But, in addition to the great artistic results, the material advantages of this discovery are very considerable. Firstly, by any of the old processes-photo-painting, as one might
call them-are always monotonous and wanting in dura-
bility. By oil painting on the photograph, the employment of water-colors, or even of transparent media, the cost of
production was immensely increased. And this was not als, because to obtain really artistic effects it was necessary to
employ artists of such a degree of talent as is rarely found
in country towns, where one does not find every in country towns, where one does not find every day a Mil-
lais, a Dickinson, or a Nadar. Now the photographer can o it all himself. So much the better for those who are neither painters nor draughtsmen. It appears that the cost
of the colored photographs produced by the Germeuil Bonof the colored photographs produced by the Germeuil Bon-
naud process is very little, if anything, more than the or inary uncolored ones. So we get at the price of an ordiary carte-de-visite a photograph in unchangeable and un-
ading colors. * Read before the Photographic Society of Great Britain. 